\title{
Bid Activates Multiple Mitochondrial Apoptotic Mechanisms in Primary Hepatocytes After Death Receptor Engagement
}

\author{
YONGGE ZHAO,* WEN-XING DING,* TING QIAN, ${ }^{\ddagger}$ SIMON WATKINS, $§$ JOHN J. LEMASTERS, ${ }^{\ddagger}$ and \\ XIAO-MING YIN* \\ Departments of *Pathology, and \$Cell Biology and Physiology, University of Pittsburgh School of Medicine, Pittsburgh, Pennsylvania; and \\ *Department of Cell and Developmental Biology, University of North Carolina at Chapel Hill, Chapel Hill, North Carolina
}

Background \& Aims: Activation of Fas or tumor necrosis factor receptor 1 (TNF-R1) on hepatocytes leads to apoptosis, which requires mitochondria activation. The pro-death $\mathrm{Bcl}-2$ family protein, Bid, mediates this pathway by inducing mitochondrial releases of cytochrome $c$ and other apoptotic factors. How Bid activates mitochondria has been studied in vitro with isolated mitochondria. We intended to study the mechanisms in intact hepatocytes so that findings could be made in a proper cellular context and would be more physiologically relevant. Methods: Hepatocytes were isolated from wild-type and bid-deficient mice and treated with antiFas or TNF- $\alpha$. Mechanisms of mitochondria activation were dissected with genetic, biochemical, and morphologic approaches. Results: bid-deficient hepatocytes were much more resistant to apoptosis. Bid was required for permeability transition and mitochondria depolarization in addition to the previously defined release of cytochrome $c$. Permeability transition inhibitors cyclosporin $A$ and aristolochic acid could inhibit mitochondria activation effectively, but not as much as the deletion of the bid gene, and they could not inhibit Bak oligomerization. In addition, mitochondria depolarization also could be induced by caspases, whose activation was mainly dependent on Bid. Conclusions: Bid may activate mitochondria by 2 mechanisms, one is related to permeability transition and the other is related to Bak oligomerization. Bid can further affect mitochondria potentials by indirectly regulating caspase activity. This in vivo study provides novel findings not previously disclosed by in vitro studies, and indicates the importance of several mechanisms in contributing Bid-mediated mitochondria dysfunction that could be potential cellular targets of intervention.

$\mathrm{H}$ epatocyte apoptosis induced by the activation of the death receptor Fas or tumor necrosis factor receptor 1 (TNF-R1) may account for the pathogenesis of a number of liver diseases. ${ }^{1-3}$ Both in vitro and in vivo models have been established to study the apoptosis mechanisms. Fas can be activated by anti-Fas antibodies, and TNF-R 1 can be activated by TNF- $\alpha$ or TNF- $\alpha$ inducers, such as lipopolysaccharide, in the in vivo models. ${ }^{4-9}$ In both models, caspases are activated and critical to hepatocyte apoptosis, which can be suppressed by caspase inhibitors. ${ }^{6,8-11}$

A significant phenomenon observed in the in vivo studies is the need for mitochondrial activation for the efficient execution of the death program. Deletion of Bid, a pro-death Bcl-2 family molecule functioning on the mitochondria, can render hepatocytes resistant to death. ${ }^{12,13}$ Bid can be activated proteolytically by caspase- 8 after death receptor activation and the truncated Bid is translocated to the mitochondria to induce cytochrome $c$ and Smac release, ${ }^{12-14}$ which are important for effective caspase activation and for the progression of the death program.

The mechanism of these Bid-mediated mitochondrial events is not understood completely. In vitro studies conducted with isolated mitochondria indicate that Bid does not cause mitochondrial swelling, permeability transition, and mitochondria depolarization. ${ }^{15-19}$ However, whether this is the case in cells is not known. From this point, it was reported that cyclosporin A (CsA), by itself or in combination with trifluoperazine, could block cytochrome $c$ release in cultured hepatocytes stimulated with anti-Fas or TNF- $\alpha{ }^{8,9}$ CsA is an inhibitor of mitochondrial permeability transition (PT) pore, which interacts with mitochondria cyclophillin $\mathrm{D},{ }^{20}$ and whose effects could be enhanced significantly by trifluoperazine or aristolochic acid (Ara).9,21-23 Thus, these studies suggest that PT may be important for cytochrome $c$ release in hepatocytes after death receptor engagement. When the in vivo data are taken into consideration, these

\footnotetext{
Abbreviations used in this paper: ActD, Actinomycin D; Ara, aristolochic acid; CsA, cyclosporin A; CHX, cycloheximide; MTT, 3 (-4,5-dimethylthiazol-2-yl)2, 5-diphenyltetrazolium bromide; PT, permeability transition; TMRM, tetramethyrhodamine methyl ester; TNF-R1, tumor necrosis factor receptor 1 .

(C) $\mathbf{2 0 0 3}$ by the American Gastroenterological Association 0016-5085/03/\$30.00 doi:10.1016/S0016-5085(03)01066-7
} 
studies would also suggest that Bid may induce cytochrome $c$ release by affecting permeability transition.

The current study was performed to address how Bid activates the mitochondria in cells in terms of its relationship with permeability transition, CsA, and caspases. We found that in a hepatocyte culture system, in which bid-deficient hepatocytes were much more resistant to TNF- $\alpha$ - or anti-Fas-induced apoptosis, mitochondria activation was also deficient in these cells, including permeability transition, mitochondria depolarization, and cytochrome $c$ release. The PT inhibitor, CsA, in combination with Ara, suppressed depolarization and cytochrome $c$ release in wild-type cells to an extent close to, but not equivalent to, that caused by bid deficiency. These data support the notion that Bid may activate mitochondria apoptosis machinery through both a CsAsensitive and a CsA-insensitive mechanism. The latter is likely related to Bak oligomerization because it could not be suppressed by the chemicals. In addition, mitochondria depolarization, but not cytochrome $c$ release, could also be caused by the feedback effects of downstream effector caspases. Taken together, these data indicated that the effect of Bid on mitochondria, including permeability transition, cytochrome $c$ release, and mitochondria depolarization, can be mediated by multiple mechanisms based on their sensitivities to inhibitors of permeability transition and caspases.

\section{Materials and Methods}

\section{Mice}

Mice deficient in bid were established by gene targeting and had been back-crossed to the $\mathrm{C} 57 \mathrm{BL} / 6$ background for 12 generations. ${ }^{12,13}$ Wild-type and bid-deficient mice used in this study were littermates and weighed about 25-30 g. They were maintained as homozygotes in a specific pathogen-free facility on the campus in compliance with the National Institutes of Health and University of Pittsburgh policies.

\section{Establishment of Primary Hepatocyte Culture}

Murine hepatocytes were isolated using the collagenase digestion method as previously described. ${ }^{24-26}$ Cells were cultured in William's medium E with all standard supplements on Falcon Primaria 24-well plates (Falcon 3847; Becton-Dickinson, Franklin Lakes, NJ) at a density of $8 \times 10^{4}$ cells/well for cell viability analysis and immunostaining, or $5 \times 10^{6}$ cells/ 100-mm collagen-coated dishes for Western blot and caspase activity assays. Cells were allowed to attach to the plate for 2-3 hours or overnight, before they were washed again with medium and treated with various chemicals as indicated in all the figure legends.

\section{Determination of Cell Viability and Apoptosis}

Cell viability was determined mainly by the following 2 methods. The tetrazolium salt method used (3,4.5-dimethylthiazol-2-yl)2,5-diphenyltetrazolium bromide (MTT) and examined its conversion to colored formazan as a way to measure cell growth and viability. This assay was performed essentially as described previously. ${ }^{27}$ Alternatively, cells were first fixed with $4 \%$ paraformaldehyde and then stained with Hoechst $33342(5 \mu \mathrm{g} / \mathrm{mL})$. Apoptotic cells showing nuclear condensation and/or fragmentation were quantified by digital microscopy.

\section{Detection of Permeability Transition and Mitochondrial Depolarization by Confocal and Conventional Fluorescence Microscopy}

Cell culture and confocal microscopy were performed essentially as described previously. ${ }^{8,9,28}$ Briefly, hepatocytes were plated in a 4-well chamber (Nunc, Naperville, IL) at $1 \times 10^{5}$ cells/well and cultured at $37^{\circ} \mathrm{C}$. At the designated time points after treatment, cells were loaded with $0.5 \mu \mathrm{mol} / \mathrm{L}$ of TMRM (Molecular Probes, Eugene, OR) for 15 minutes, followed by $1 \mu \mathrm{mol} / \mathrm{L}$ of Calcein AM (Molecular Probes) for another 15 minutes..$^{8,9,28}$ Cells were then monitored on a heating stage $\left(37^{\circ} \mathrm{C}\right)$ of a laser scanning confocal microscope (Leica, Bannockburn, IL). For the conventional fluorescence microscopy study, hepatocytes were plated in a 24 -well plate (Falcone 3847 ) at $1 \times 10^{5}$ cells/well, stimulated and then loaded with 0.5 $\mu \mathrm{mol} / \mathrm{L}$ of $\mathrm{TMRM}$ for 15 minutes at $37^{\circ} \mathrm{C}$ before being examined by digital microscopy.

\section{Analysis of Cytochrome c Release}

Immunostaining essentially was performed as described previously. ${ }^{29}$ Briefly, hepatocytes in the 24-well plates were fixed in $4 \%$ paraformaldehyde and permeabilized with $0.4 \%$ Triton X-100 with $10 \%$ normal goat serum. Cells were then stained with an anti-cytochrome $c$ antibody (clone 6H2.B4; BD PharMingen, San Diego, CA; 1:500) followed by Cy3-conjugated goat anti-mouse antibody $(1 \mu \mathrm{g} / \mathrm{mL}$; Jackson Immunoresearch, West Grove, PA). Cells were counterstained with Hoechst $33342(5 \mu \mathrm{g} / \mathrm{mL})$ before digital microscopy was conducted. Western blot analysis was conducted as previously described. ${ }^{30-32}$ Cells were harvested, washed, and then treated with $0.05 \%$ digitonin in isotonic buffer A $(10 \mathrm{mmol} / \mathrm{L}$ HEPES, $150 \mathrm{mmol} / \mathrm{L} \mathrm{NaCl}, 1.5 \mathrm{mmol} / \mathrm{L} \mathrm{MgCl}_{2}, 1 \mathrm{mmol} / \mathrm{L}$ ethylene glycol-bis( $\beta$-aminoethyl ether)- $N, N, N^{\prime}, N^{\prime}$-tetraacetic acid, $\mathrm{pH}$ 7.4) containing a cocktail of protease inhibitors for 2 minutes at room temperature. Cells were centrifuged at $10,000 \mathrm{rpm}$ for 10 minutes and the supernatants (digitoninreleased cytosol) were analyzed by Western blot for the mitochondria-released cytochrome $c$ and other cytosol proteins, such as $14-3-3$. 


\section{Bak Cross-Linking}

This was conducted as previously described. ${ }^{30,32}$ Essentially, cells were harvested, washed, and first permeabilized with $0.05 \%$ digitonin in isotonic buffer $\mathrm{A}$ at room temperature for 2 minutes as described earlier. After centrifugation at $5000 \mathrm{rpm}$ for 10 minutes at $4^{\circ} \mathrm{C}$, the pellet was extracted further with ice-cold lysis buffer (2\% CHAPS in buffer A containing protease inhibitors) for 60 minutes at $4{ }^{\circ} \mathrm{C}$ to obtain the membrane fraction. The membranes extracted with CHAPS were incubated with $1 \mathrm{mmol} / \mathrm{L}$ Dithiobis succinimidylpropionate (Pierce, Rockford, IL) or the solvent, dimethyl sulfoxide, on a nutator for 30 minutes at room temperature, followed by separation on a $12 \%$ sodium dodecyl sulfatepolyacrylamide gel electrophoresis (SDS-PAGE) and Western blot with an anti-Bak antibody (Upstate Biotechnology, Lake Placid, NY).

\section{Analysis of Caspase Activities}

At a designated time point, hepatocytes were scraped off the plates, washed, and resuspended in buffer B (150 $\mathrm{mmol} / \mathrm{L} \mathrm{NaCl}, 20 \mathrm{mmol} / \mathrm{L}$ Tris. $\mathrm{pH} \mathrm{7.2,} 1 \mathrm{mmol} / \mathrm{L}$ dithiothreitol, $1 \%$ Triton X-100, or NP-40 with a cocktail of protease inhibitors). After 3 cycles of freezing and thawing, the lysates were cleared by centrifugation. Caspase activities were measured by incubating $20 \mu \mathrm{g}$ of proteins with $25 \mu \mathrm{mol} / \mathrm{L}$ of fluorescent substrates in an analysis buffer $(20 \mathrm{mmol} / \mathrm{L} \mathrm{KCl}, 20$ $\mathrm{mmol} / \mathrm{L}$ Pipes $\mathrm{pH} 7.4,4 \mathrm{mmol} / \mathrm{L} \mathrm{MgCl}_{2}, 2 \mathrm{mmol} / \mathrm{L}$ dithiothreitol) at $37^{\circ} \mathrm{C}$ for $30-60$ minutes. The fluorescence signals were determined by a fluorescence spectrometer (LS 50B; Perkin Elmer, Wellesley, MA) at $400 \mathrm{~nm} / 505 \mathrm{~nm}$ (excitation/ emission).

\section{Results}

\section{Hepatocytes Deficient in bid Are Refractory to Anti-Fas or TNF- $\alpha$}

To study the mechanism by which Bid activates the mitochondria in the cell, we had set up a primary hepatocyte culture and verified the role of Bid in antiFas- or TNF- $\alpha$-induced apoptosis in this system. Cell viability was monitored at different times after the treatment by MTT assay (Figure 1A), nuclear staining (Figure $1 B$ ), trypan blue staining, and visual inspection by phase microscopy (data not shown). Data from all these assays were comparable and showed that a majority of wild-type hepatocytes were killed by anti-Fas or TNF- $\alpha$ in the presence of cycloheximide (CHX) or actinomycin $\mathrm{D}$ (ActD) within 24 hours (Figure $1 A$ ). Nuclear fragmentation and condensation could be observed easily (Figure $1 B$ ). Although anti-Fas-induced killing progressed more quickly than that induced by TNF- $\alpha$, in either treatment hepatocytes deficient in bid were significantly more resistant than the wild-type cells as determined by all the criteria. The difference between wild- type and bid-deficient cells was not in the rate of viability loss, but seemed to be in the time when death became noticeable. The kinetics indicated that bid-deficient cells had a lag of 6-8 hours to progress through the death program. Thus, the data suggest that the role of Bid is to engage a mechanism that allows an early activation of the death program in this cultured system. Also, in this system anti-Fas or TNF- $\alpha$ alone could not kill the hepatocyte owing to the activation of nuclear factor $\kappa \mathrm{B}, 5,7,9$ whose effects, however, could be suppressed by either ActD or CHX. These chemicals alone had no effects on cell viability at the dose used in the time frame analyzed (data not shown). Blocking nuclear factor $\kappa \mathrm{B}$ activation with a nondegradable dominant-negative I- $\mathrm{B}$ mutant ${ }^{9}$ resulted in similar findings (data not shown).

Engagement of Fas or TNF-R1 by the agonistic antibody Jo- 2 or the ligand TNF- $\alpha$, respectively, can lead to the activation of an initiator caspase, caspase- 8 , and effector caspases. ${ }^{33}$ Consistent with the viability analysis, both types of caspases were activated earlier in anti-Fastreated hepatocytes than in TNF- $\alpha$-treated cells (Figure $1 C$ ). However, in both cases, activation of these caspases was delayed significantly in time and reduced in magnitude in bid-deficient hepatocytes either by enzymatic activity measurement (Figure $1 C$ ) or by Western blot for caspase- 3 or caspase-3 substrate cleavage (data not shown). The higher caspase- 8 activity in the wild-type hepatocytes was likely due to the higher caspase- 3 activity, which could engage in a feedback amplification of pro-caspase- 8 processing. ${ }^{14,34}$ There is no defect in caspase- 8 activation in bid-deficient hepatocytes. ${ }^{14}$ At the later time point, the difference in the caspase activities between the 2 types of hepatocytes treated with TNF$\alpha /$ ActD became smaller, indicating that additional Bidindependent mechanisms were activated by then. ${ }^{13}$

These data confirmed and extended previous findings from animal studies, showing the dominant role of Bid in death receptor-mediated hepatocyte apoptosis. Furthermore, it indicated that the culture system was adequate to address the mechanism by which Bid induces mitochondria damage.

\section{Bid-Dependent Cytochrome $c$ Release Is Accompanied With Mitochondria Permeability Transition and Mitochondria Depolarization}

The Bid-dependent pathway is mediated by mitochondria and is a more potent mechanism for caspase- 3 activation through the apoptosome. ${ }^{12,13,35}$ Indeed $\mathrm{Bid}$ was cleaved in wild-type hepatocytes after Fas/TNF-R1 engagement (Figure 2A). Correspondingly, cytochrome $c$ 
A
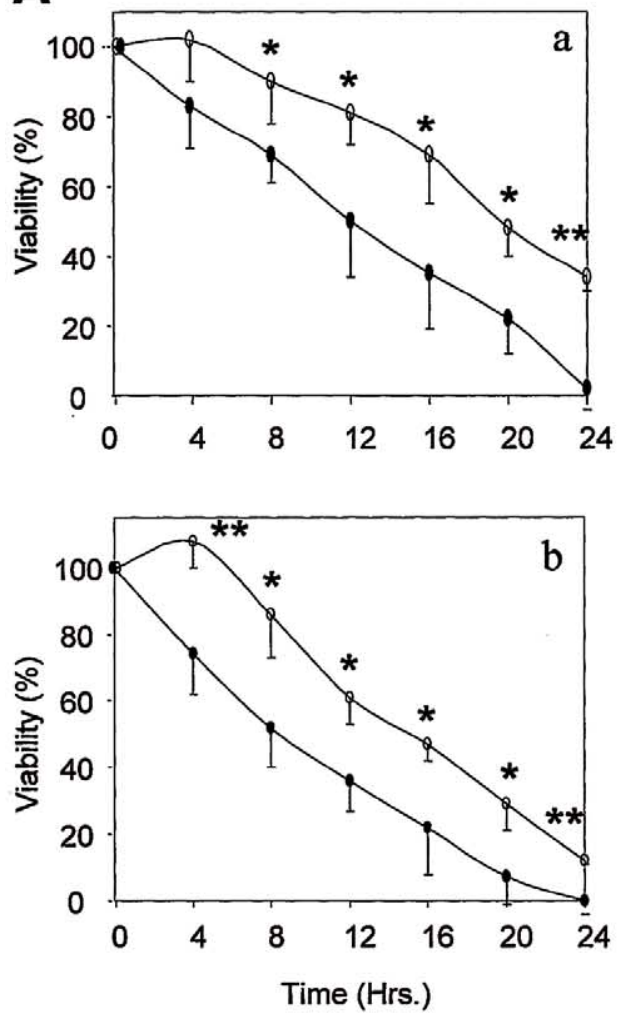

B

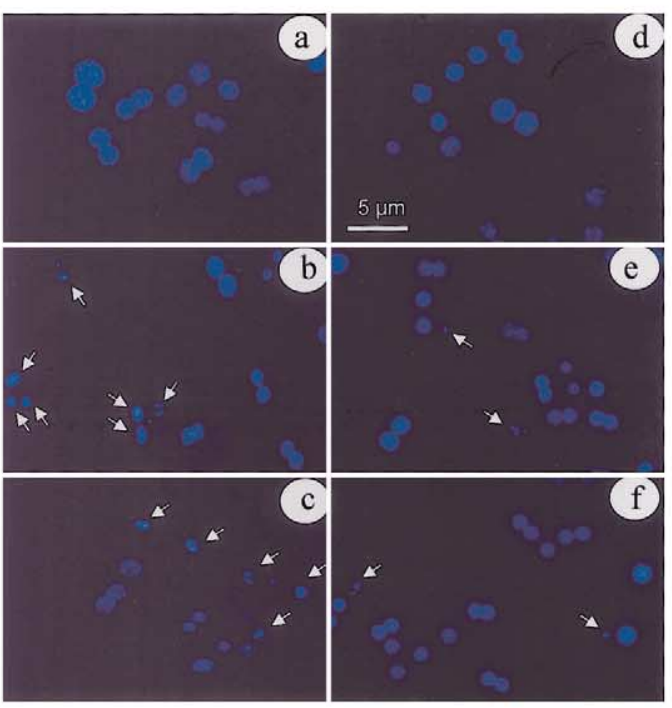

C
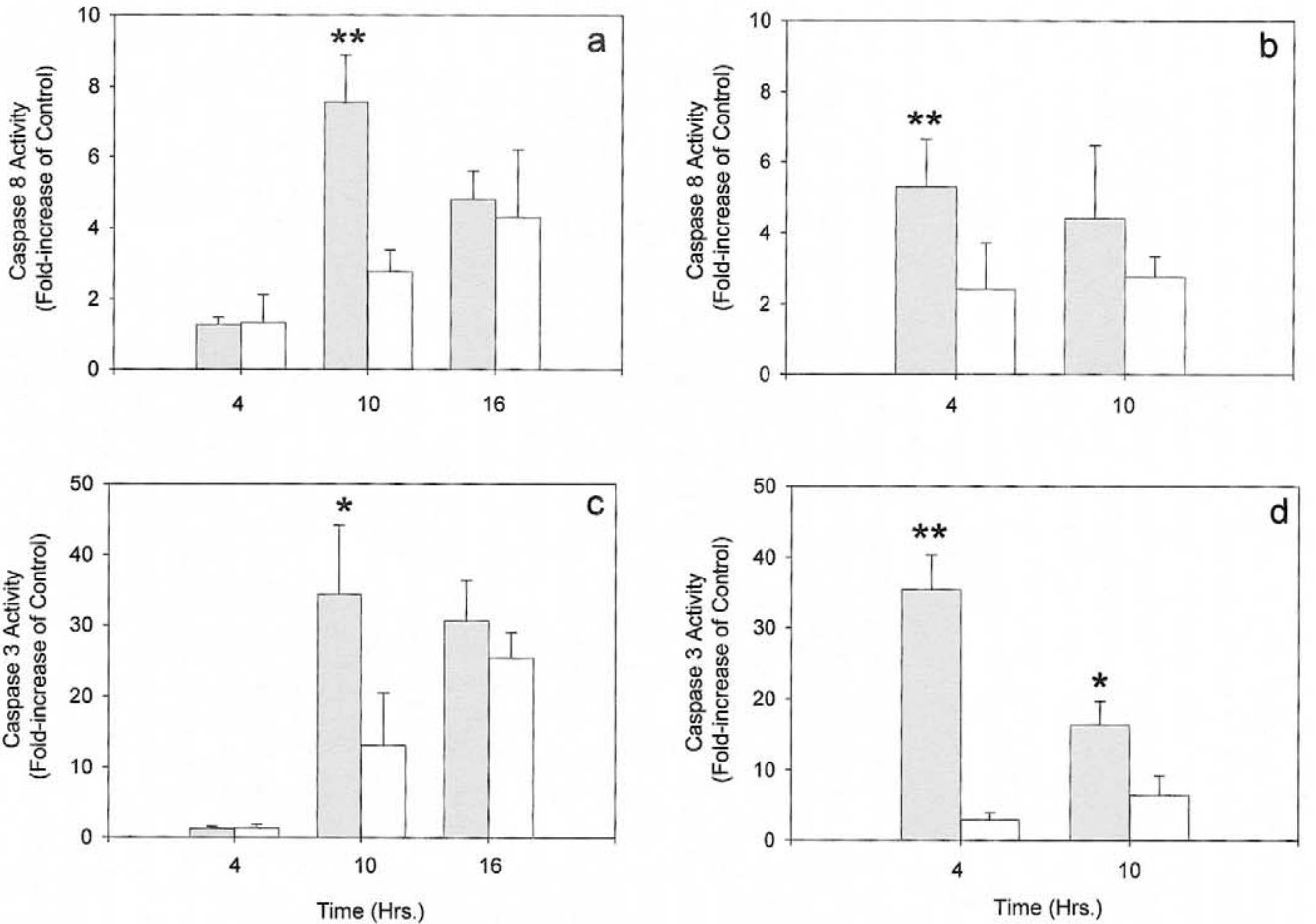

Figure 1. bid-deficient hepatocytes are refractory to TNF- $\alpha$ or anti-Fas antibody treatment. $(A)$ Hepatocytes were prepared from $(\bullet)$ wild-type and (O) bid-deficient mice and treated with TNF- $\alpha$ (10 ng/mL, Sigma) (a) or anti-Fas $(0.5 \mu \mathrm{g} / \mathrm{mL}$, BD PharMingen, clone Jo-2) (b) in the presence of ActD $(50 \mathrm{ng} / \mathrm{mL})$ or $\mathrm{CHX}(10 \mu \mathrm{g} / \mathrm{mL})$, respectively. Viabilities were determined at designated time points by MTT assay and standardized to nontreated controls (mean \pm SD). (B) Representative micrographs of Hoechst 33342 nuclear staining of $(a-c)$ wild-type or $(d-f)$ bid-deficient hepatocytes cultured for 8 hours in the $(a, d)$ absence or the $(b, e)$ presence of TNF- $\alpha / \operatorname{ActD}$ or $(c, f)$ anti-Fas/CHX. Arrows indicate fragmented or condensed nuclei. $(C)$ Activities of $(a, b)$ caspase-8 and $(c, d)$ caspase-3 in $(\square)$ wild-type or $(\square)$ bid-deficient hepatocytes treated with $(a, c)$ TNF- $\alpha$ /ActD or $(b, d)$ anti-Fas/CHX for 4,10 , or 16 hours were measured using Ac-IETD-AFC or Ac-DEVD-AFC, respectively. The activities were represented as fold-increase of nontreated controls (mean $\pm \mathrm{SD}$ ). ActD or $\mathrm{CHX}$ alone did not cause cell death more significantly than controls without treatment or with vehicle only (data not shown). For $A$ and $C$, a $t$ test was conducted between the wild-type and bid-deficient groups ( $* P<$ $0.05 ; * *>0.01)$. 
A

Time (Hrs.):

Treatment:
4

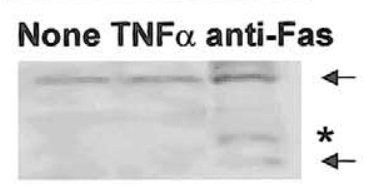

8

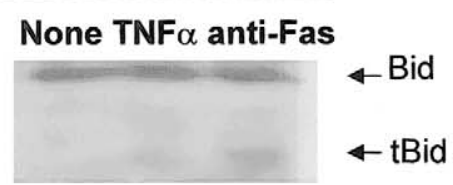

B
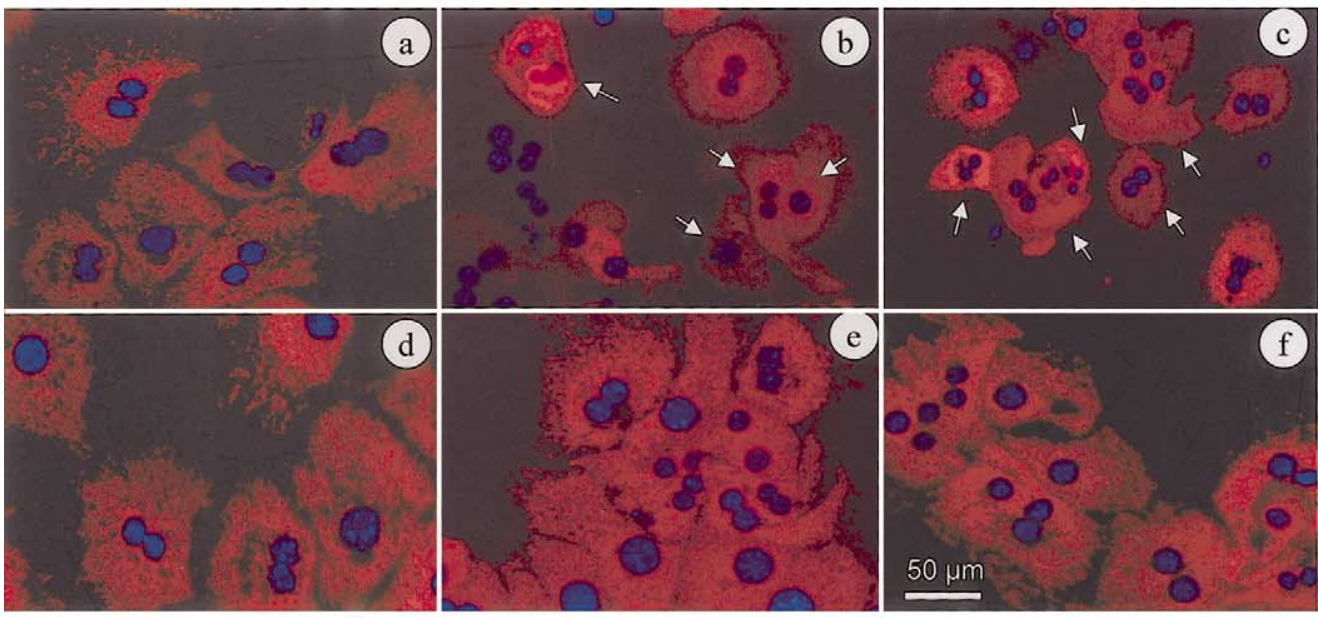
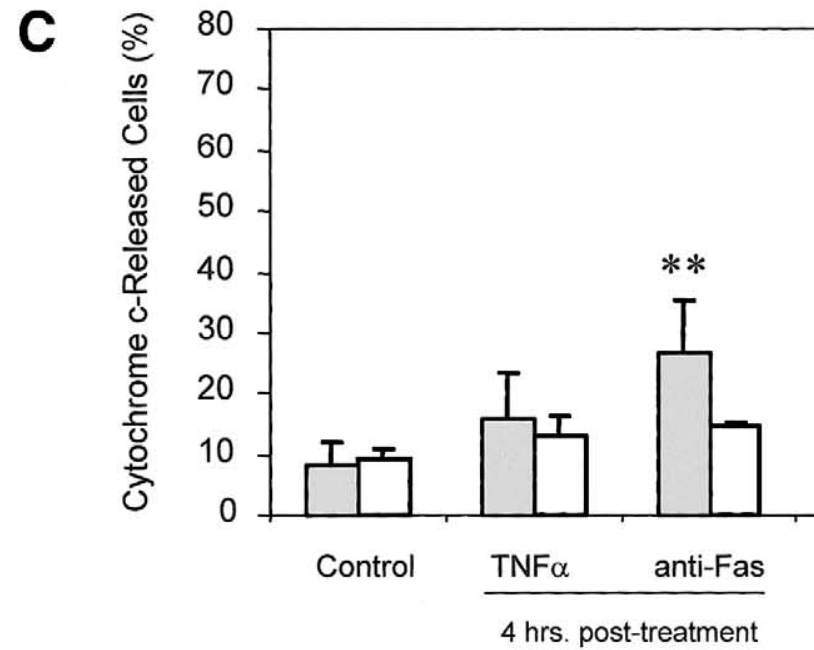

4 hrs. post-treatment

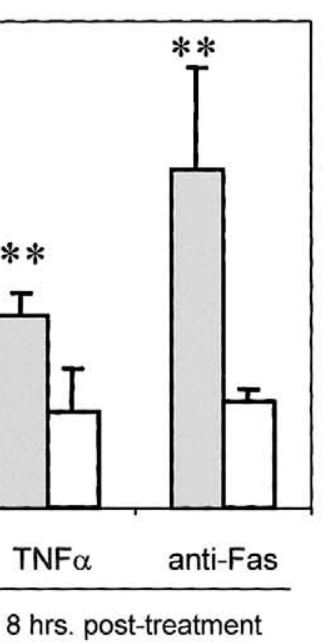

Figure 2. Bid is activated in hepatocytes treated with TNF- $\alpha$ or anti-Fas and is responsible for cytochrome $c$ release. $(A)$ Bid cleavage in wild-type hepatocytes cultured with TNF- $\alpha$ / ActD or anti-Fas/CHX for 4 or 8 hours. Whole-cell lysates were prepared and subjected to SDS-PAGE followed by Western blot with an anti-Bid antibody. Cleaved Bid could be detected in anti-Fas-treated cells as early as 4 hours after treatment, but became apparent in TNF- $\alpha$-treated cells at 8 hours as well. *Nonspecific band. (B) Cytochrome $c$ release in $(a-c)$ wild-type or (d-f) bid-deficient hepatocytes after treatment with (b, e) TNF- $\alpha$, (c, f) anti-Fas, or $(a, d)$ vehicle control for 8 hours. Cells were immunostained with an anticytochrome $c$ antibody and counterstained with Hoechst 33324. Arrows indicate cells with typical cytoplasmic distribution of cytochrome $c .(C)$ Quantification of cells with cytochrome $c$ release in $(\square)$ wild-type and ( $\square$ ) bid-deficient hepatocytes treated with TNF- $\alpha$ or anti-Fas for 4 or 8 hours. Cells with cytoplasmic distribution of cytochrome $c$ were recorded and quantified with a fluorescence microscope. The numbers were expressed as the percentage of total cells with cytochrome $c$ staining (mean $\pm \mathrm{SD}$ ). A $t$ test was performed between wildtype and bid-deficient groups $(* * P<0.01)$. was released as determined by immunofluorescence microscopy (Figure $2 B$ ). Staining of the hepatocyte with an anti-cytochrome $c$ antibody could clearly define cells with mitochondrial or cytoplasmic localization of the protein. We only evaluated cells with intact morphology to focus on changes at the early stage based on the kinetics of viability and caspase activation, and avoided the inclusion of apparently dead cells that might have altered cytochrome $c$ staining owing to nonspecific later events. Under the current regimen, the percentage of wild-type cells with a cytoplasmic distribution of cytochrome $c$ increased dramatically after anti-Fas or TNF- $\alpha$ treatment. In contrast, cytochrome $c$ release was minimal in bid-deficient hepatocytes after the same treatment (Figure 2C). The differences between the wild-type and the bid-deficient groups were statistically significant. These results also were confirmed by Western blot analysis (see below in Figure 5). 
Figure 3. Anti-Fas or TNF- $\alpha$ induces mitochondrial permeability transition and depolarization in wild-type but not in bid-deficient hepatocytes. Wild-type (bid $+/+, 2$ upper panels) and bid-deficient (bid -/-, 2 lower panels) hepatocytes were treated with $(A)$ TNF- $\alpha /$ ActD or (B) anti-Fas/CHX for 6 or 0.5 hours, respectively. Cells were then loaded with $0.5 \mu \mathrm{mol} / \mathrm{L}$ of tetramethylrhodamine methyl ester (TMRM) for 15 minutes, followed by $1 \mu \mathrm{mol} / \mathrm{L}$ of $\mathrm{Cal}-$ cein $\mathrm{AM}$ for another $15 \mathrm{~min}$ utes. The plates were then mounted onto the heating stage $\left(37^{\circ} \mathrm{C}\right)$ of a laser scanning confocal microscope (Leica). The cells were examined in the next several hours. Representative micrographs of Calcein AM and TMRM staining are shown for cells treated with (A) TNF- $\alpha$ /ActD for a total of 7 or 9 hours and for $(B)$ cells treated with anti-Fas/CHX for 1 or 4 hours as indicated.
A

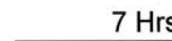

$7 \mathrm{Hrs}$

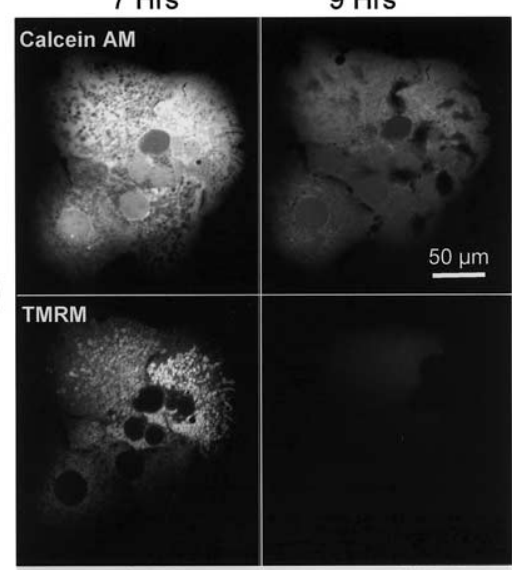

bid (+/+)

bid (-/-)

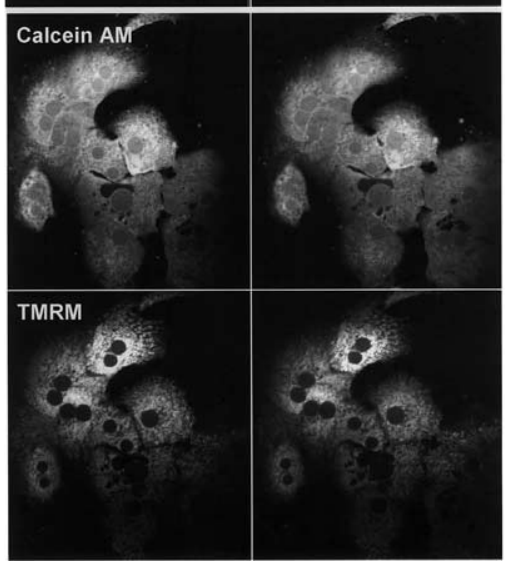

B
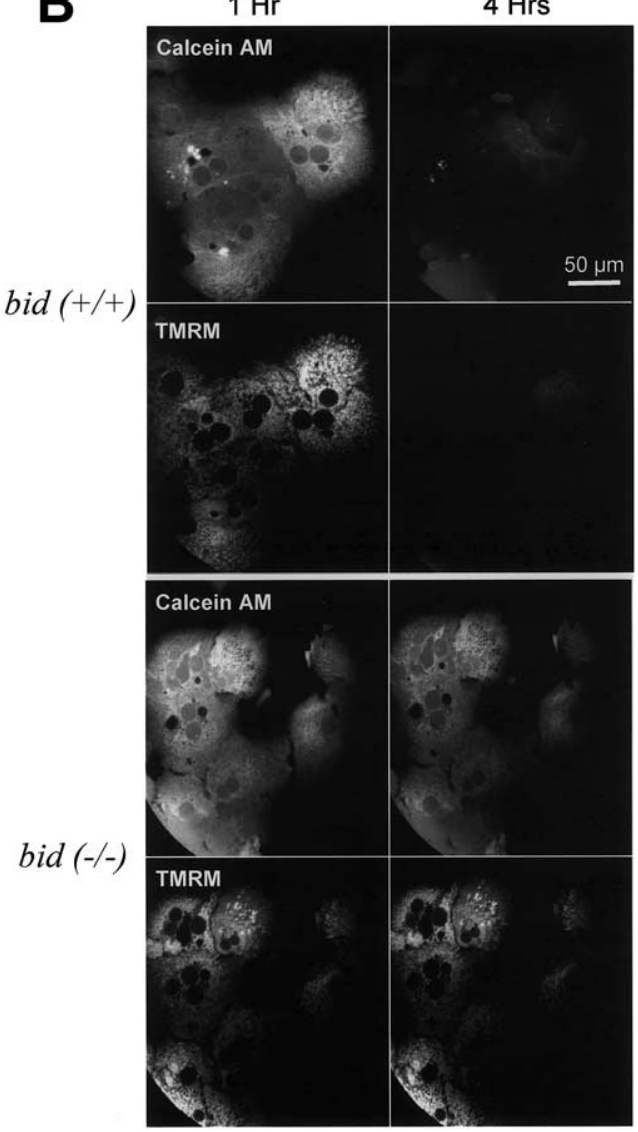

A key issue in the activation of the mitochondrial pathway is how cytochrome $c$ is released. Several mechanisms involving the mitochondrial permeability transition have been proposed. ${ }^{22,35-37}$ Inhibitors of PT, such as CsA, have been shown to be effective in blocking antiFas- or TNF- $\alpha$-induced hepatocyte death in culture. ${ }^{8,9}$ Because Bid played a significant role in this type of death by inducing cytochrome $c$ release, we examined whether Bid could be involved in the induction of PT in cultured hepatocytes. If so, PT would be reduced in bid-deficient hepatocytes after the treatment.

To accomplish this, we adopted an imaging method that monitors the distribution of a fluorescence probe, Calcein AM, across the mitochondria. Under normal conditions, the mitochondrial inner membrane is impermeable to Calcein AM and thus this green fluorescence dye is distributed exclusively in the cytosol.8,9,28,38 Redistribution of Calcein AM from the cytosol to the mitochondria signifies the onset of mitochondrial permeability transition. ${ }^{8,9,28,38}$ Calcein AM redistribution into the mitochondria could be observed around 3 hours after anti-Fas treatment and around 8 hours after TNF- $\alpha$ treatment in wild-type hepatocytes (Figure 3). CsA was able to block the altered distribution of Calcein AM (data not shown). ${ }^{8,9,28,38}$ In contrast, bid-deficient hepatocytes showed unchanged Calcein AM distribution in the same time frame (Figure 3). Thus, the data indicated that anti-Fas- and TNF- $\alpha$-induced permeability transition, as defined by this technique, could be caused in large part by the effects of Bid.

We also found that significant depolarization in the wild-type hepatocytes occurred in association with the Calcein AM redistribution (Figure 3). However, bid-deficient cells seemed to be able to maintain their mitochondrial transmembrane potentials (Figure 3). The change in transmembrane potentials was thus parallel to that in Calcein AM redistribution (Figure 3). To gain an understanding of these changes across the population (Figure $4 A$ ), we quantified the number of depolarized cells, which indicated that a significantly greater amount of wild-type hepatocytes than bid-deficient cells failed to maintain the mitochondrial potentials after the treatment (Figure $4 B$ ).

Taken together, it seems that the effects of Bid on mitochondrial permeability transition and transmembrane potentials were parallel to its effects on mitochondrial cytochrome $c$ release. These results further suggested that there could be mechanistic relationships among these events. 
A

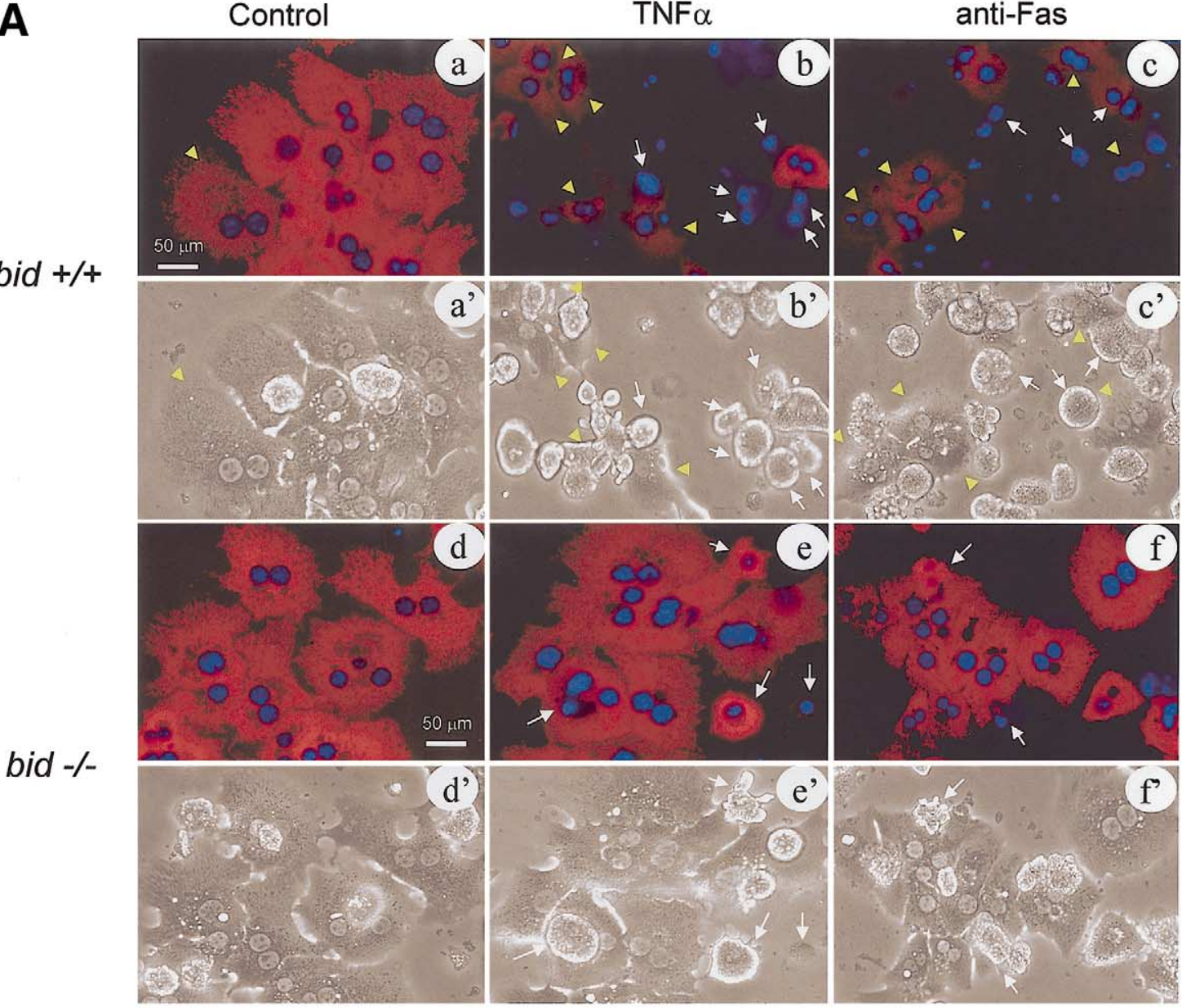

B

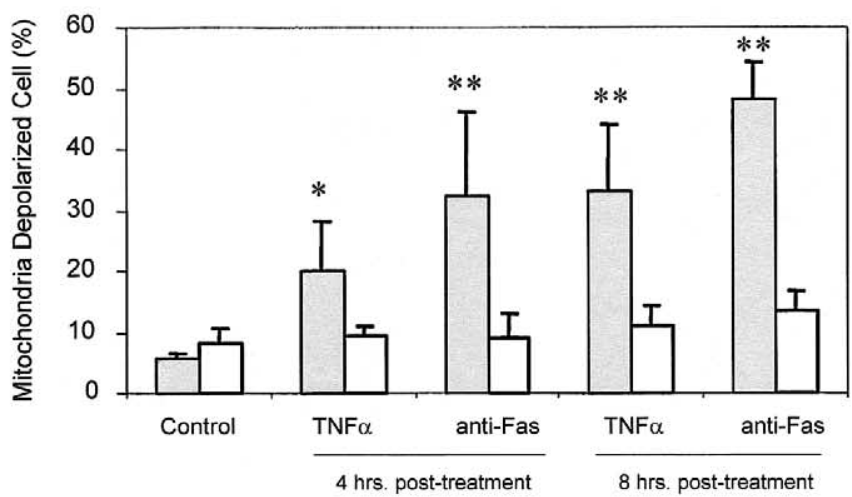

Figure 4. bid-deficient hepatocytes are resistant to anti-Fas-or TNF- $\alpha$-induced mitochondrial depolarization. $(A)\left(a-c, a^{\prime}-c^{\prime}\right)$ Wild-type and $(d-f$, $\left.d^{\prime}-f^{\prime}\right)$ bid-deficient hepatocytes were treated with $\left(a, a^{\prime}, d, d^{\prime}\right)$ vehicle control, $\left(b, b^{\prime}, e, e^{\prime}\right)$ TNF- $\alpha /$ ActD, or $\left(c, c^{\prime}, f, f^{\prime}\right)$ anti-Fas/CHX. Eight hours later, TMRM $(0.5 \mu \mathrm{mol} / \mathrm{L})$ was added for 30 minutes. Cells were counterstained with Hoechst 33324 and then observed under a fluorescence microscope. Representative fields were first selected under $\left(a^{\prime}-f^{\prime}\right)$ phase contrast and then the (a-f) TMRM and Hoechst signals of the cells were recorded with a digital camera. Many depolarized cells showed apoptotic morphology with fragmented nuclei and rounded cell shape (arrows), although some still kept normal morphology (arrowheads). A significantly greater number of bid-deficient hepatocytes maintained normal potentials and morphology. $(B)$ Depolarized $(\square)$ wild-type or $(\square)$ bid-deficient cells after TNF- $\alpha$ or anti-Fas treatment for 4 or 8 hours were quantified and the number was expressed as the percentage of total cells (polarized and depolarized, based on phase-contrast observation) (mean \pm SD). The difference between wild-type and bid-deficient groups was significant $(* P<0.05 ; * * P<0.01)$. 
A

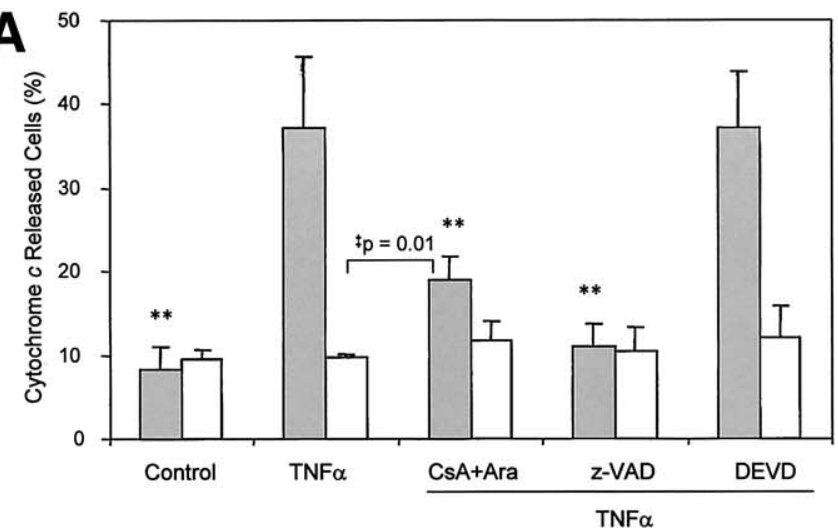

B

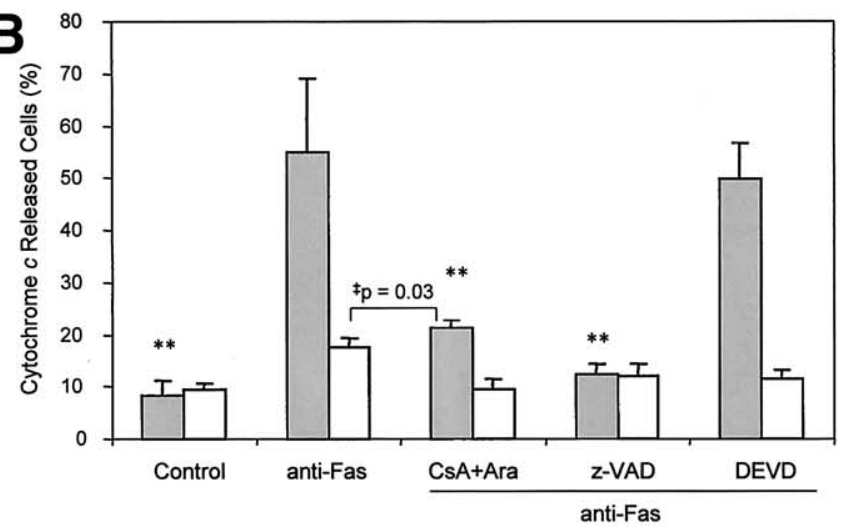

C

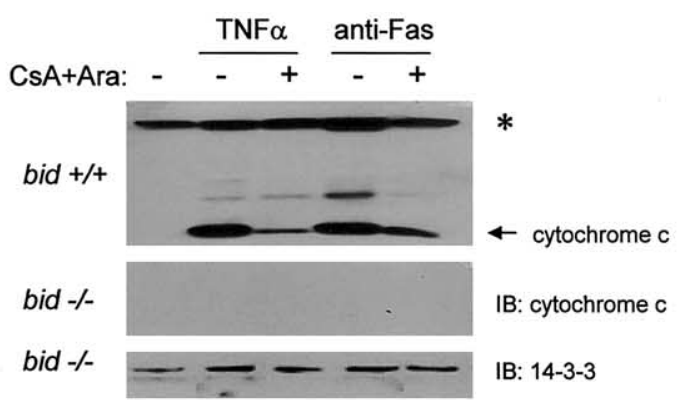

Figure 5. Differential effects of PT and caspase inhibitors on cytochrome $c$ release. ( $\square$ ) Wild-type or $(\square)$ bid-deficient hepatocytes were treated with $(A, C, D)$ TNF- $\alpha /$ ActD or $(B-D)$ anti-Fas $/ C H X$ for 8 hours. CsA $(10 \mu \mathrm{mol} / \mathrm{L})$ plus Ara $(50 \mu \mathrm{mol} / \mathrm{L})$, z-VAD-fmk (50 $\mu \mathrm{mol} / \mathrm{L})$, or DEVD-CHO (50 $\mu \mathrm{mol} / \mathrm{L}$ ) was added at the beginning of the culture in selected groups as indicated. Controls were vehicle only. At the end of the culture, 2 assays were performed for cytochrome $c$ release. $(A, B)$ Cells were fixed and immunostained for cytochrome $c$ as shown in Figure 2 . Cells with cytoplasmic distribution of cytochrome $c$ were quantified and the numbers were expressed as the percentage of the total cells with cytochrome $c$ staining (mean $\pm \mathrm{SD}$ ). $(C)$ Alternatively, treated cells were processed with digitonin and the released cytosolic fractions were analyzed by SDS-PAGE and immunoblotted with anti-cytochrome $c$ or anti-14-3-3 antibody (for loading control of bid-deficient samples). Asterisk in the anti-cytochrome $c$ blot of wild-type samples indicates a cross-reactive product, which serves as a spurious loading control for these samples. $(D)$ Densitometry was conducted on blots as represented in panel $C$ and fold-increase of the density over the control treatment was determined (mean \pm SD from 3 experiments). All statistical analyses were performed with a $t$ test. $(A, B)$ Comparisons were made between $(A)$ TNF- $\alpha-$ or $(B)$ anti-Fas-treated groups and other treatment groups for wild-type hepatocytes except for the pairs indicated by $\neq$. (D) Comparisons were made between TNF- $\alpha$ - or anti-Fas-treated groups alone and those also with CSA/Ara or ZVAD, except for the pairs indicated by $\neq$. Comparisons that reached statistical significance are shown $(* * P<0.01)$. $\neq t$ test was performed between wild-type cells treated with TNF- $\alpha$ or anti-Fas in the presence of CsA/Ara and bid-deficient cells treated with TNF- $\alpha$ or anti-Fas only ( $P$ values are indicated for $A, B, D)$. ActD, CHX, CsA/Ara, or caspase inhibitor alone did not cause more significant changes than the controls with vehicle only (data not shown).

\section{Bid Could Activate Multiple Mechanisms to Induce Cytochrome $c$ Release and Mitochondria Depolarization}

To investigate these relationships, we used PT inhibitors and compared their effects with those of bid deficiency on the mitochondrial events induced by the death receptor activation. Wild-type and bid-deficient hepatocytes were treated as described earlier, but in the presence of CsA together with Ara. The quantitative data indicated that CsA/Ara could suppress TNF- $\alpha$ - or antiFas-induced cytochrome $c$ (Figure $5 A-D$ ). The percentage of cells that did release cytochrome $c$ was reduced to a level close to that of similarly treated bid-deficient cells, but in the absence of CsA/Ara (Figure $5 A, B$ ). This was confirmed by immunoblot analysis, which indicated cytochrome $c$ release only in wild-type but not bid-deficient treated cells and that CsA/Ara effectively, but not completely, suppressed the process (Figures $5 C, D$ ). In parallel, CsA/Ara could also efficiently reduce the number of depolarized wild-type cells after the treatment, although again not to the same level observed in equivalently treated bid-deficient cells without CsA/Ara (Figure 6). Thus, it seemed that cytochrome $c$ release and mitochondria depolarization could be mediated mainly through a Bid-dependent, CsA-sensitive mechanism. However, because bid-deficiency consistently resulted in less cytochrome $c$ release (by both immunostaining and immunoblotting analyses) and a better protection against 

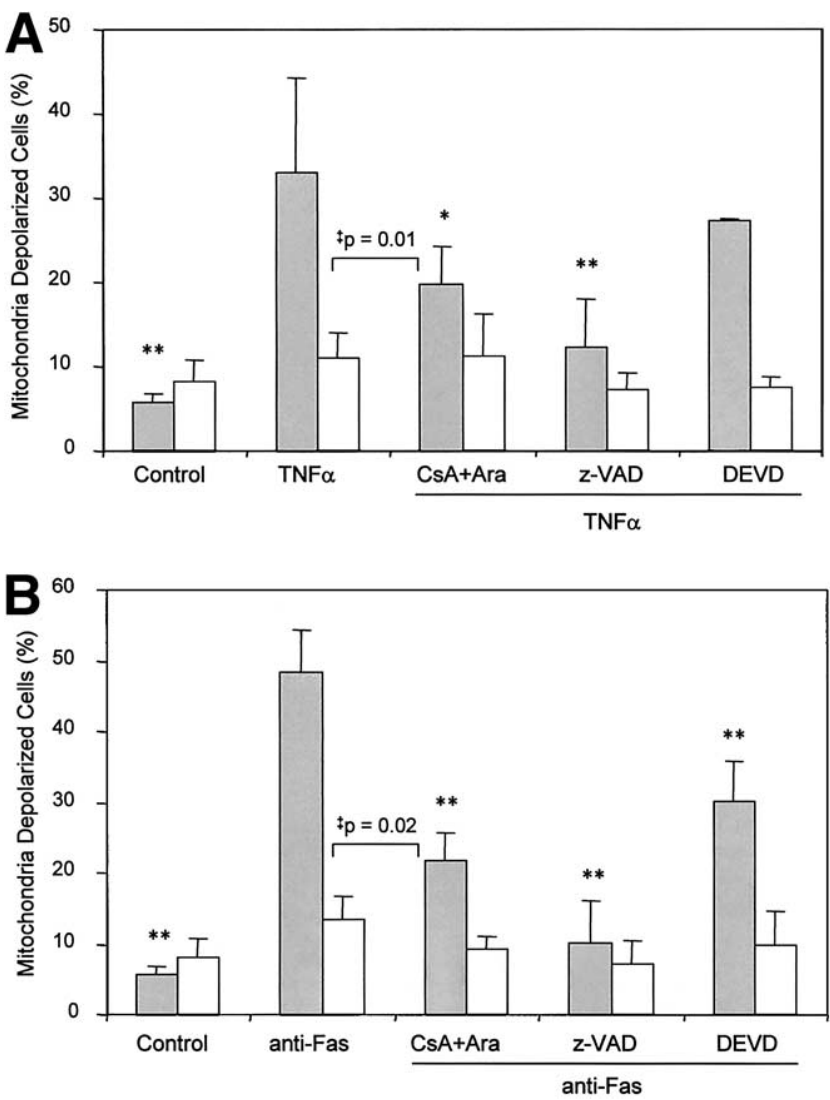

Figure 6. Differential effects of PT and caspase inhibitors on mitochondrial depolarization. $(\square)$ Wild-type or $(\square)$ bid-deficient hepatocytes were treated with $(A)$ TNF- $\alpha /$ ActD or $(B)$ anti-Fas/CHX for 8 hours. Other chemicals were added as indicated in Figure 5 legend. Controls are vehicle only. TMRM $(0.5 \mu \mathrm{mol} / \mathrm{L})$ was added at the end of the culture for 30 minutes. Depolarized cells were quantified and the number was expressed as the percentage of total cells (polarized and depolarized, based on phase-contrast observation) (mean $\pm S D$ ). Statistical analysis was performed with a $t$ test between $(A)$ TNF- $\alpha-$ or $(B)$ anti-Fas-treated groups and other treatment groups for wild-type hepatocytes except for the pair indicated by $\neq$ is indicated. Comparisons that reached statistical significance are shown $(* * P<0.01$; $* P<0.05)$. $¥ A$ A test was performed between wild-type cells treated with $(A)$ TNF- $\alpha$ or $(B)$ anti-Fas in the presence of CsA/Ara and biddeficient cells treated with TNF- $\alpha$ or anti-Fas only ( $P$ value is indicated). ActD, CHX, CsA/Ara, or caspase inhibitor alone did not cause more significant changes than the controls with vehicle only (data not shown).

depolarization than CsA/Ara $(P<0.05$ or $<0.01$ in both cases, Figures 5 and 6 ), it seemed that Bid might activate a CsA-insensitive mechanism as well.

One possible CsA-insensitive mechanism could be the oligomerization of the multidomain prodeath molecule, $\mathrm{Bak}$, as previously indicated on isolated mitochondria. ${ }^{39}$ Bak is expressed constitutively on the mitochondria and activated in a Bid-dependent manner during death receptor-initiated hepatocyte death. ${ }^{18,40}$ Indeed, cross-linking of the membrane fractions of TNF- $\alpha$ - or anti-Fastreated hepatocytes indicated that Bak oligomerization was induced and that this process was not affected by CsA/Ara treatment (Figure 7).

To differentiate mitochondrial changes resulting from downstream caspase activation, we examined the effects of caspase inhibitors in a similar way. An effector caspase inhibitor, N-acetyl-Asp-Glu-Val-Asp-aldehyde (DEVD$\mathrm{CHO}$ ), had little effect on cytochrome $c$ release (Figure 5), but had observable effects on mitochondrial depolarization, particularly in anti-Fas-treated cells (Figure 6). This suggests that the contribution of the effector caspases to mitochondrial depolarization was present, but perhaps independent of cytochrome $c$ release. On the other hand, a pan-caspase inhibitor, benzyloxy-carbonylVal-Ala-Asp-fluomethylketone (z-VAD-fmk), could almost completely inhibit cytochrome $c$ release and membrane depolarization (Figures 5 and 6). This was likely

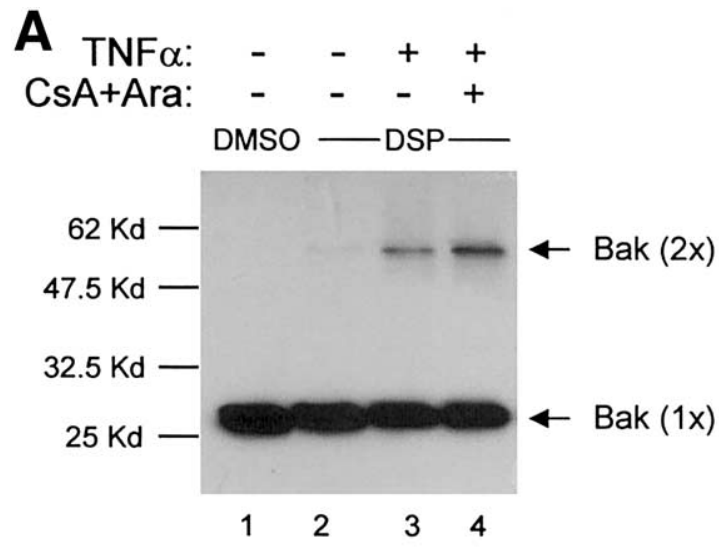

B

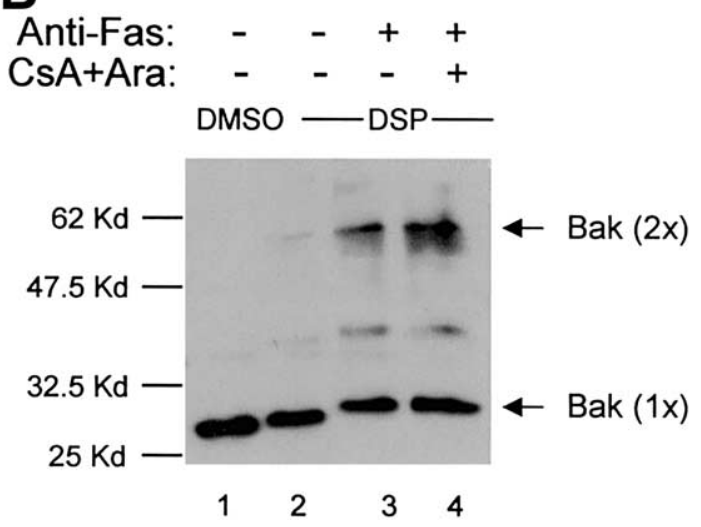

Figure 7. Bid-induced Bak oligomerization is not affected by CsA/Ara treatment. Wild-type hepatocytes were treated with $(A)$ TNF- $\alpha / A c t D$ or (B) anti-Fas/CHX in the presence or absence of CsA/Ara for 6-8 hours and then harvested. The membrane fraction was isolated and cross-linked with Dithiobis succinimidylpropionate (DSP, lanes 2-4) or with the solvent dimethyl sulfoxide alone (DMSO, lane 1) as described in the Materials and Methods section. The proteins were then separated on 12\% SDS-PAGE and immunoblotted with the anti-Bak antibody. Arrows indicate the monomer and dimer form of Bak, which run at the position of 27 kilodaltons and 54 kilodaltons, respectively. Data shown represent 4 experiments performed. 
due to a combined suppression of both downstream effector caspases and the upstream caspase- 8 , which would lead to the suppression of Bid activation in this system. In summary, these data suggest that mitochondrial depolarization could be induced, to a larger extent, by Bid's effect on mitochondria (directly or indirectly via other molecules), and to a lesser extent, by a feedback effect of effector caspases. On the other hand, cytochrome $c$ release was dependent mainly on the activity of the initiator caspase, caspase- 8 , and Bid. The effect of $z-$
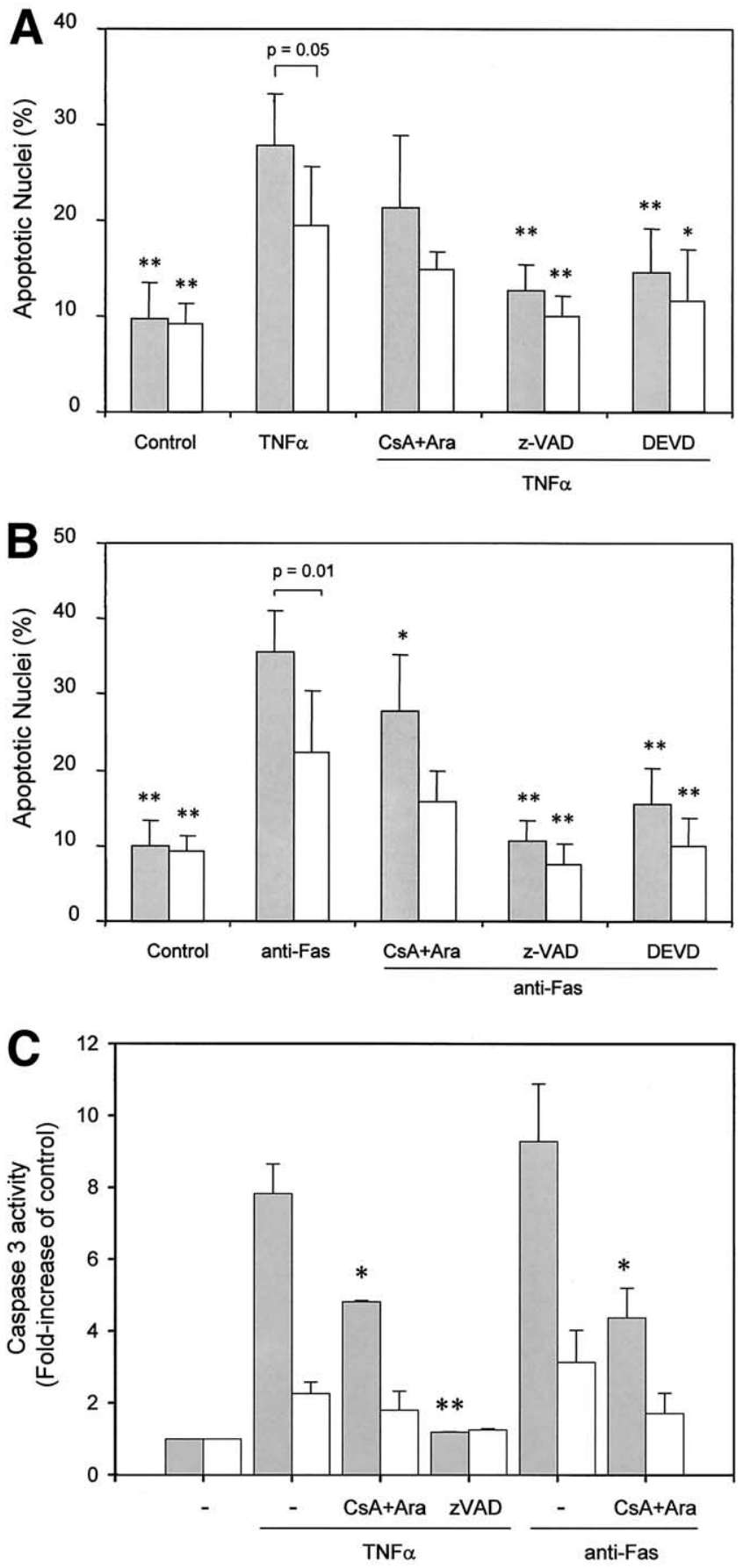

VAD-fmk on mitochondria activation was equivalent to that of bid deficiency, but was more significant than that of CsA/Ara, further suggesting that not all of the Bid effects were mediated by the CsA/Ara-sensitive mechanism.

\section{Caspase Inhibitors Are More Effective Than PT Inhibitors in Suppressing Terminal Apoptotic Events in Anti-Fas-/TNF- $\alpha$ Treated Hepatocytes In Vitro}

When the effects of caspase and PT inhibitors on parameters of the terminal apoptotic changes, such as caspase activation, nuclear fragmentation/condensation (Figure 8), and viability (data not shown) were analyzed, a different pattern was observed. Both z-VAD-fmk and DEVD-CHO were very effective in suppressing the terminal apoptotic changes, likely because these were mediated mainly by the effector caspases. Loss of the bid gene also provided significant protection, although to a lesser degree compared with the caspase inhibitors. Caspase inhibitors could provide further protection in bid-deficient cells (Figure $8 A$ and $B$ ), perhaps by inhibiting caspase activation independently of Bid (Figure $8 C)$. Interestingly, CsA/Ara provided less protection than bid deficiency (Figure $8 A$ ). Protection by CsA alone was minimal, and by bongkrakic acid, another PT inhibitor, was not observed at all (data not shown). Death in the presence of CsA/Ara was still apoptotic as determined by the nuclear staining and also by the effective suppression by the caspase inhibitors (Figure 8). One possible explanation for the dissociation between the inhibitory effects of CsA/Ara on the mitochondrial events and the end-stage apoptotic events is the presence of the CsA-/Ara-insensitive killing mechanism, and/or the mi-

Figure 8. Differential effects of PT and caspase inhibitors on cell viability. ( $\square$ ) Wild-type or $(\square)$ bid-deficient hepatocytes were treated with $(A, C)$ TNF- $\alpha / \operatorname{ActD}$ or $(B, C)$ anti-Fas/CHX for 8 hours. Other chemicals were added as indicated in Figure 5 legend. $(A, B)$ Controls are vehicle only. At the end of the culture, cells were fixed and stained with Hoechst 33342. Cells with apoptotic nuclei (i.e., fragmented or condensed) (see Figure 1), were quantified. The numbers are expressed as the percentage of total cells with nuclear staining (mean $\pm \mathrm{SD}$ ). (C) Alternatively, cytosolic fractions were prepared and analyzed for caspase-3 activities. Statistic analysis was performed between $(A)$ TNF- $\alpha$ or $(B)$ anti-Fas treatment groups and all other treatment groups for $(\square)$ wild-type and $(\square)$ bid-deficient. (C) Comparisons were made between TNF- $\alpha$ - or anti-Fas-treated groups alone and those also with CsA/Ara or ZVAD. Only comparisons that reached significance are shown $(* P<0.05 ; * * P<0.01)$. The difference between wild-type and bid-deficient cells after TNF- $\alpha$ or anti-Fas treatment alone also was significant $(P<0.05$ and 0.01 , respectively). ActD, CHX, CsA/Ara, or caspase inhibitor alone did not cause more significant changes than the controls with vehicle only (data not shown). 
tochondria-independent or Bid-independent killing mechanism (see Discussion section later). This is confirmed by the significant presence of residual effector caspase activities in CsA-/Ara-treated cells (Figure 8C). Thus, these data were consistent with other observations and suggest that the CsA-/Ara-sensitive mechanism mediates only a part, although a larger part, of the effects of Bid, and that Bid-mediated apoptosis is only a part, although a larger part, of the cell death programs induced by anti-Fas or TNF- $\alpha$ in the cultured primary hepatocytes (Figure 9).

\section{Discussion}

A number of studies on death receptor-induced hepatocyte apoptosis have been conducted, but some of the key questions remained unanswered, particularly those about mitochondria activation. Because the analysis can be performed in a proper cellular environment, the cell culture system provides a unique way to examine these issues, which may not be readily addressable by the animal studies or the in vitro reconstitution analysis. We thus aimed to determine the mechanism of mitochondria activation in cultured murine primary hepatocytes after TNF- $\alpha$ or anti-Fas antibody treatment.

We found that bid-deficient hepatocytes had significant protection against TNF- $\alpha$ or anti-Fas, compared with the wild-type cells. However, these cells eventually died from the same stimulation. Thus, the death was delayed but not prevented by the loss of the bid gene in this culture system. The death was apoptotic, rather than necrotic, and the Bid-independent mechanisms, similar to the Bid-dependent mechanism, were likely mediated by caspases because z-VAD-fmk protected both wildtype and bid-deficient cells very well. Although yet to be defined thoroughly, the potential Bid-independent mechanisms may include a direct activation of caspase-3 by caspase- $8,{ }^{14,41,42}$ the activation of the ASK-1/JNK pathway, ${ }^{43,44}$ and the activation of RAIDD-caspase-2 pathway. ${ }^{45,46}$ However, in cultured hepatocytes, the Biddependent pathway was the predominant mechanism for caspase activation because caspase activities were reduced significantly in bid-deficient cells after stimulation. One reason that the Bid-independent killing is more evident in cultured cells than in animals ${ }^{12,13,40}$ could be the less favorable culture condition, which may exacerbate Bidindependent caspase activation, but not be the use of ActD or CHX, because the same phenomenon was observed with a more specific nuclear factor $\kappa B$ inhibitor, a nondegradable I- $\mathrm{KB}$ mutant ${ }^{9}$ (data not shown). Although ActD or $\mathrm{CHX}$ would be a less favorable chemical than

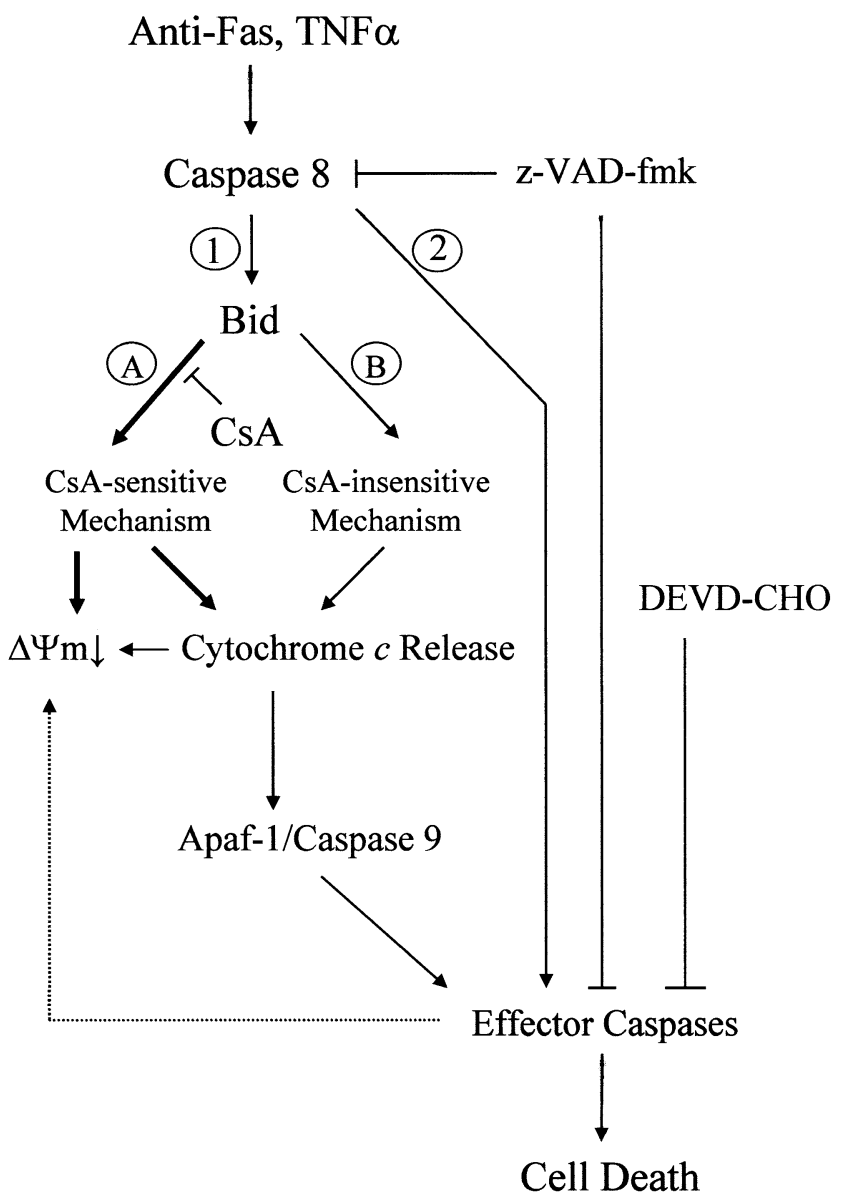

Figure 9. Schematic representation of Bid-mediated mitochondrial events in cultured hepatocytes stimulated with anti-Fas or TNF- $\alpha$. The activation of death receptors, Fas or TNF-R1, by anti-Fas or TNF- $\alpha$, respectively, can activate an initiator caspase, caspase-8, which in turn activates effector caspases by a Bid-dependent (1) and a Bid-independent (2) mechanism. Bid may activate both a $(A)$ CsA-sensitive mechanism, which CsA can suppress, and a $(B)$ CsA-insensitive mechanism, which CsA cannot suppress. Both mechanisms can lead to cytochrome $c$ release and membrane depolarization. Based on the use of CsA and Ara, it seems that the CsA-sensitive mechanism may contribute more significantly to cytochrome $c$ release, as represented by a thicker arrow. The nature of CsA-sensitive and -insensitive mechanisms is subject to debate, although PT is one likely candidate for the CsA-sensitive mechanism. On the other hand, CsA-insensitive mechanisms may be related to oligomerization of Bak and/or Bax. Mitochondria depolarization ( $\Delta \psi \mathrm{m} \downarrow)$ in vivo is caused mainly by the direct effect of Bid, resulting from events upstream and/or downstream of cytochrome $c$ release. Depolarization can also be in part caused by effector caspases through a feedback mechanism (represented by the dotted arrow). The pan-caspase inhibitor, z-VAD-fmk, provides the best protection because it inhibits both Bid-dependent and Bid-independent pathways. The effector caspase inhibitor, DEVD-CHO, is quite effective in suppressing cell death, but ineffective in suppressing the mitochondrial apoptotic events. In contrast, bid deficiency or CsA/Ara provides better protection against the mitochondrial events than the terminal apoptotic changes because the latter could also be caused by the Bid-independent mechanism. 
the I- $\kappa \mathrm{B}$ mutant for sensitizing cells owing to potential nonspecific toxicity, this has not become a concern in the current system, for a short incubation period $(<24 \mathrm{~h})$ and low doses of chemicals were used.

Nevertheless, the dominance of the Bid pathway and the dependency of cytochrome $c$ release on Bid found in the stimulated hepatocytes indicated that the culture system was an appropriate one to analyze the mechanism of the Bid-dependent pathway at the level of mitochondria. How Bid induces cytochrome $c$ release is not well understood, although studies primarily based on in vitro reconstitution systems indicate that the mitochondrial outer membranes remain intact during the process, with little mitochondrial swelling ${ }^{17,18}$ and membrane depolarization. ${ }^{17,19}$ In contrast, Bid requires Bak or Bax to release cytochrome $c,{ }^{15,18,40}$ which could form special transmembrane channels on the outer membranes. ${ }^{35}$ Thus, it seems that the role of PT pore in cytochrome $c$ release, the activation of which was traditionally characterized by mitochondrial swelling and outer membrane disruption, was not readily shown.

Paradoxically, studies using primary hepatocyte culture found that cytochrome $c$ release induced by anti-Fas or TNF- $\alpha$ could be suppressed by CsA alone ${ }^{8}$ or in combination with trifluoperazine, ${ }^{9}$ both are classic inhibitors of the PT pore. These studies thus suggest that the pore could be involved in cytochrome $c$ release in cells. Moreover, because Bid is required for cytochrome $c$ release in this system (Figure 3), it could be inferred that Bid might activate PT, which CsA can inhibit. Indeed, we found that CsA in combination with Ara, another enhancing agent for CsA, ${ }^{21,47,48}$ could suppress cytochrome $c$ release in anti-Fas or TNF- $\alpha$-treated wild-type hepatocytes. However, this inhibition was less significant than that caused by bid deletion. The differences between the 2 conditions were small and varied in experiments, but were consistently observable and statistically significant $(P=0.01$ and 0.03 for TNF- $\alpha$ and anti-Fas treatment, respectively). These data suggest that Bid can trigger a CsA-sensitive mechanism and a less-dominant CsA-insensitive mechanism for the release of cytochrome c. Alternatively, a CsA-insensitive unregulated PT pore may become involved in part. ${ }^{37}$ It has to be pointed out that the effects of CsA do not seem to be mediated by its inhibition on calcineurin, a serine-threonine phosphatase, because a more specific calcineurin inhibitor, FK506, does not have the same effects as CsA on mitochondria activation. 49,50

It had been difficult to reconcile the cellular studies with the in vitro reconstitution studies. However, a recent study re-examined some of the issues using the in vitro system and found that cytochrome $c$ release induced by Bid could be mediated by 2 different mechanisms. ${ }^{39}$ One was responsible for the initial release of free cytochrome $c$ present in the intermembrane space through a Bak-dependent mechanism. The other caused a dramatic remodeling of mitochondrial cristae, which mobilized the cytochrome $c$ storage. This portion of cytochrome $c$ constituted the majority (85\%) of the total released. Interestingly, the latter event could be suppressed by CsA. Our observations with the cellular system are consistent with this study in that distinguishable mechanisms of cytochrome $c$ release could be discerned based on CsA sensitivity and the CsA-sensitive mechanism seems to be the major one.

The CsA-insensitive mechanism could be attributed to outer membrane permeabilization mediated by Bid-activated Bak or Bax oligomerization, which is important for the initial release of a smaller amount of cytochrome c. ${ }^{18,39,40}$ Our study supports this notion because CsA/Ara could not suppress Bak oligomerization in the cultured hepatocytes stimulated with TNF- $\alpha$ or anti-Fas (Figure 7) and indicates that at least Bak oligomerization could serve as a CsA-insensitive mechanism. But the nature of the CsA-sensitive or CsA-suppressible mechanism remains elusive. Cellular studies indicate that this mechanism may be considered as PT because CsA is a classic inhibitor of it, which acts on mitochondrial cyclophilin D. $8,9,20,28,38$ To some extent, the CsA-insensitive mechanism also may be considered to be related to PT because it has been suggested that one conductance mode of PT is CsA unregulated. ${ }^{37}$ However, the fact that most mitochondria remain intact without swelling after treatment with truncated Bid in vitro ${ }^{16-19,39}$ suggests that if PT is indeed induced by Bid, it probably does not stand in open mode, but rather flickers or rapidly cycles through an open and closed status. ${ }^{37,38}$ This, however, will still allow the nonspecific redistribution of small molecular weight solutes, such as Calcein AM, across the mitochondria. ${ }^{8,9,28,38}$ It is not clear how this mode of PT will then cause cytochrome $c$ release without disrupting the mitochondria outer membrane. It is therefore possible that the Bid-activated CsA-sensitive mechanism can also represent other mitochondrial targets that CsA can affect, such as the mitochondrial cristae whose remodeling can lead to the mobilization of stored cytochrome $c{ }^{39}$

A change parallel to the redistribution of Calcein AM is mitochondria depolarization, which was also observed in hepatocytes after death receptor activation. No significant mitochondrial depolarization was observed in recombinant tBid-treated mitochondria in vitro. ${ }^{17,19,39}$ However, studies based on many cellular systems often 
found that depolarization was accompanied by cytochrome $c$ release, ${ }^{35,51,52}$ although the mechanisms could be quite diverse. One possible mechanism is that additional factors may be required for depolarization to occur in a scale large enough to be detected. Caspases could be one of the factors in the cell. ${ }^{52}$ Both z-VAD-fmk and DEVD-CHO could suppress mitochondrial depolarization in anti-Fas- or TNF- $\alpha-$ treated hepatocytes. One may not be able to separate the inhibitory effect of z-VAD-fmk on Bid activation (via caspase- 8 inhibition) from that on effector caspases. However, the partial inhibition of depolarization by DEVD-CHO in treated hepatocytes indicates that at least some of the depolarization events could be attributed to the effects of effector caspases. Thus, a direct in vivo effect of Bid, alone or in combination with other factors, on mitochondrial potentials is possible. In this scenario, depolarization may not result from a massive outer membrane disruption, but from the flickering of the PT pore and/or the massive release of cytochrome $c$ after the activation of the CsAsensitive mechanism. This may explain why depolarization was also sensitive to CsA suppression to a large extent. Because the release of total cytochrome $c$ can be completed in minutes, ${ }^{52}$ it probably would not be surprising that Calcein AM redistribution, cytochrome $c$ mobilization, and membrane depolarization were kinetically inseparable under the current observation conditions.

In conclusion, our data support the model that a Bid-mediated mitochondria pathway is a dominant apoptosis pathway in hepatocytes after death receptor activation and that Bid can activate a CsA-sensitive pathway in addition to a CsA-insensitive pathway to induce mitochondrial release of cytochrome $c$ (Figure 9). These mechanisms may also be operative in other types of cells undergoing mitochondria-dependent apoptosis initiated by other death stimuli.

\section{References}

1. Bradham CA, Plumpe J, Manns MP, Brenner DA, Trautwein C. Mechanisms of hepatic toxicity. I. TNF-induced liver injury. Am J Physiol 1998;275:G387-G392.

2. Rust C, Gores GJ. Apoptosis and liver disease. Am J Med 2000; 108:567-574.

3. Jaeschke H, Gores GJ, Cederbaum Al, Hinson JA, Pessayre D, Lemasters JJ. Mechanisms of hepatotoxicity. Toxicol Sci 2002; 65:166-176.

4. Ogasawara J, Watanabe-Fukunaga R, Adachi M, Matsuzawa A, Kasugai T, Kitamura Y, Itoh N, Suda T, Nagata S. Lethal effect of the anti-Fas antibody in mice. [published erratum appears in Nature 1993;365:568] Nature 1993;364:806-809.

5. Leist M, Gantner F, Bohlinger I, Germann PG, Tiegs G, Wendel A. Murine hepatocyte apoptosis induced in vitro and in vivo by TNF-alpha requires transcriptional arrest. J Immunol 1994;153: 1778-1788.

6. Jaeschke H, Fisher MA, Lawson JA, Simmons CA, Farhood A, Jones DA. Activation of caspase 3 (CPP32)-like proteases is essential for TNF-alpha-induced hepatic parenchymal cell apoptosis and neutrophil-mediated necrosis in a murine endotoxin shock model. J Immunol 1998;160:3480-3486.

7. Ni R, Tomita Y, Matsuda K, Ichihara A, Ishimura K, Ogasawara J, Nagata S. Fas-mediated apoptosis in primary cultured mouse hepatocytes. Exp Cell Res 1994;215:332-337.

8. Bradham CA, Qian T, Streetz K, Trautwein C, Brenner DA, Lemasters $\mathrm{JJ}$. The mitochondrial permeability transition is required for tumor necrosis factor alpha-mediated apoptosis and cytochrome c release. Mol Cell Biol 1998;18:6353-6364.

9. Hatano E, Bradham CA, Stark A, limuro Y, Lemasters JJ, Brenner DA. The mitochondrial permeability transition augments Fas-induced apoptosis in mouse hepatocytes. J Biol Chem 2000;275: $11814-11823$.

10. Rodriguez I, Matsuura K, Ody C, Nagata S, Vassalli P. Systemic injection of a tripeptide inhibits the intracellular activation of CPP32-like proteases in vivo and fully protects mice against Fas-mediated fulminant liver destruction and death. J Exp Med 1996;184:2067-2072.

11. Jones RA, Johnson VL, Buck NR, Dobrota M, Hinton RH, Chow $\mathrm{SC}$, Kass GE. Fas-mediated apoptosis in mouse hepatocytes involves the processing and activation of caspases. Hepatology 1998;27:1632-1642.

12. Yin XM, Wang K, Gross A, Zhao Y, Zinkel S, Klocke B, Roth KA, Korsmeyer SJ. Bid-deficient mice are resistant to Fas-induced hepatocellular apoptosis. Nature 1999;400:886-891.

13. Zhao Y, Li S, Childs EE, Kuharsky DK, Yin X-M. Activation of pro-death Bcl-2 family proteins and mitochondria apoptosis pathway in tumor necrosis factor-alpha-induced liver injury. J Biol Chem 2001;276:27432-27440.

14. Li S, Zhao Y, He X, Kim T-H, Kuharsky DK, Rabinowich H, Chen J, Du C, Yin X-M. Relief of extrinsic pathway inhibition by the Biddependent mitochondrial release of Smac in Fas-mediated hepatocyte apoptosis. J Biol Chem 2002;277:26912-26920.

15. Desagher S, Osen-Sand A, Nichols A, Eskes R, Montessuit S, Lauper S, Maundrell K, Antonsson B, Martinou JC. Bid-induced conformational change of bax is responsible for mitochondrial cytochrome c release during apoptosis. J Cell Biol 1999;144: 891-901.

16. Kluck RM, Esposti MD, Perkins G, Renken C, Kuwana T, BossyWetzel E, Goldberg M, Allen T, Barber MJ, Green DR, Newmeyer DD. The pro-apoptotic proteins, Bid and Bax, cause a limited permeabilization of the mitochondrial outer membrane that is enhanced by cytosol. J Cell Biol 1999;147:809-822.

17. Kim TH, Zhao Y, Barber MJ, Kuharsky DK, Yin XM. Bid-induced cytochrome $c$ release is mediated by a pathway independent of mitochondrial permeability transition pore and Bax. J Biol Chem 2000;275:39474-39481.

18. Wei MC, Lindsten T, Mootha VK, Weiler S, Gross A, Ashiya M, Thompson CB, Korsmeyer SJ. tBID, a membrane-targeted death ligand, oligomerizes BAK to release cytochrome c. Genes Dev 2000;14:2060-2071.

19. Shimizu S, Tsujimoto Y. Proapoptotic BH3-only Bcl-2 family members induce cytochrome $c$ release, but not mitochondrial membrane potential loss, and do not directly modulate voltage-dependent anion channel activity. Proc Natl Acad Sci U S A 2000;97: 577-582.

20. Crompton M. The mitochondrial permeability transition pore and its role in cell death. Biochem J 1999;341:233-249.

21. Zoratti M, Szabo I. The mitochondrial permeability transition. Biochim Biophys Acta 1995;1241:139-176.

22. Bernardi P, Scorrano L, Colonna R, Petronilli V, Di Lisa F. Mitochondria and cell death. Mechanistic aspects and methodological issues. [published erratum appears in Eur J Biochem 1999; 265:847] Eur J Biochem 1999;264:687-701.

23. Pastorino JG, Tafani M, Rothman RJ, Marcineviciute A, Hoek JB, Farber JL. Functional consequences of the sustained or transient 
activation by Bax of the mitochondrial permeability transition pore. J Biol Chem 1999;274:31734-31739.

24. Seglen PO. Preparation of isolated rat liver cells. Methods Cell Biol 1976;13:29-83.

25. Klaunig JE, Goldblatt PJ, Hinton DE, Lipsky MM, Chacko J, Trump BF. Mouse liver cell culture. I. Hepatocyte isolation. In Vitro 1981;17:913-925.

26. Klaunig JE, Goldblatt PJ, Hinton DE, Lipsky MM, Trump BF. Mouse liver cell culture. II. Primary culture. In Vitro 1981;17:926-934.

27. Hansen MB, Nielsen SE, Berg K. Re-examination and further development of a precise and rapid dye method for measuring cell growth/cell kill. J Immunol Methods 1989;119:203-210.

28. Nieminen AL, Byrne AM, Herman B, Lemasters JJ. Mitochondrial permeability transition in hepatocytes induced by $\mathrm{t}-\mathrm{BuOOH}$ : NAD(P)H and reactive oxygen species. Am J Physiol 1997;272: C1286-C1294.

29. Srinivasan A, Li F, Wong A, Kodandapani L, Smidt R Jr, Krebs JF, Fritz LC, Wu JC, Tomaselli KJ. Bcl-xL functions downstream of caspase-8 to inhibit Fas- and tumor necrosis factor receptor 1-induced apoptosis of MCF7 breast carcinoma cells. J Biol Chem 1998;273:4523-4529.

30. Mikhailov V, Mikhailova M, Pulkrabek DJ, Dong Z, Venkatachalam MA, Saikumar P. Bcl-2 prevents bax oligomerization in the mitochondrial outer membrane. J Biol Chem 2001;276:18361-18374.

31. Waterhouse NJ, Goldstein JC, von Ahsen O, Schuler M, Newmeyer DD, Green DR. Cytochrome c maintains mitochondrial transmembrane potential and ATP generation after outer mitochondrial membrane permeabilization during the apoptotic process. J Cell Biol 2001;153:319-328.

32. Yi X, Yin X-M, Dong Z. Inhibition of Bid-induced apoptosis by Bcl-2: tBid insertion, Bax translocation and Bax/Bak oligomerization suppressed. J Biol Chem 2003;278:16992-16999.

33. Ashkenazi A, Dixit VM. Death receptors: signaling and modulation. Science 1998;281:1305-1308.

34. Bajt ML, Lawson JA, Vonderfecht SL, Gujral JS, Jaeschke H. Protection against Fas receptor-mediated apoptosis in hepatocytes and nonparenchymal cells by a caspase-8 inhibitor in vivo: evidence for a postmitochondrial processing of caspase-8. Toxicol Sci 2000;58:109-117.

35. Green DR, Reed JC. Mitochondria and apoptosis. Science 1998; 281:1309-1312.

36. Kroemer G, Dallaporta B, Resche-Rigon M. The mitochondrial death/life regulator in apoptosis and necrosis. Annu Rev Physiol 1998;60:619-642.

37. He L, Lemasters JJ. Regulated and unregulated mitochondrial permeability transition pores: a new paradigm of pore structure and function? FEBS Lett 2002;512:1-7.

38. Petronilli V, Miotto G, Canton M, Brini M, Colonna R, Bernardi P, Di Lisa F. Transient and long-lasting openings of the mitochondrial permeability transition pore can be monitored directly in intact cells by changes in mitochondrial calcein fluorescence. Biophys J 1999;76:725-734.

39. Scorrano L, Ashiya M, Buttle K, Weiler S, Oakes SA, Mannella CA, Korsmeyer SJ. A distinct pathway remodels mitochondrial cristae and mobilizes cytochrome $c$ during apoptosis. Dev Cell 2002;2: 55-67.

40. Wei MC, Zong WX, Cheng EH, Lindsten T, Panoutsakopoulou V, Ross AJ, Roth KA, MacGregor GR, Thompson CB, Korsmeyer SJ. Proapoptotic BAX and BAK: a requisite gateway to mitochondrial dysfunction and death. Science 2001;292:727-730.
41. Srinivasula SM, Ahmad M, Fernandes-Alnemri T, Litwack G, Alnemri ES. Molecular ordering of the Fas-apoptotic pathway: the Fas/APO-1 protease Mch5 is a CrmA-inhibitable protease that activates multiple Ced-3/ICE- like cysteine proteases. Proc Natl Acad Sci U S A 1996;93:14486-14491.

42. Stennicke HR, Jurgensmeier JM, Shin H, Deveraux Q, Wolf BB, Yang X, Zhou Q, Ellerby HM, Ellerby LM, Bredesen D, Green DR, Reed JC, Froelich CJ, Salvesen GS. Pro-caspase-3 is a major physiologic target of caspase-8. J Biol Chem 1998;273:2708427090.

43. Ichijo $\mathrm{H}$, Nishida $\mathrm{E}$, Irie $\mathrm{K}$, ten Dijke $\mathrm{P}$, Saitoh $\mathrm{M}$, Moriguchi $\mathrm{T}$, Takagi M, Matsumoto K, Miyazono K, Gotoh Y. Induction of apoptosis by ASK1, a mammalian MAPKKK that activates SAPK/ JNK and p38 signaling pathways. Science 1997;275:90-94.

44. Tang F, Tang G, Xiang J, Dai Q, Rosner MR, Lin A. The absence of NF-KB-mediated inhibition of C-Jun N-terminal kinase activation contributes to tumor necrosis factor alpha-induced apoptosis. Mol Cell Biol 2002;22:8571-8579.

45. Duan H, Dixit VM. RAIDD is a new 'death' adaptor molecule. Nature 1997;385:86-89.

46. Ahmad M, Srinivasula SM, Wang L, Talanian RV, Litwack G, Fernandes-Alnemri T, Alnemri ES. CRADD, a novel human apoptotic adaptor molecule for caspase-2, and FasL/tumor necrosis factor receptor-interacting protein RIP. Cancer Res 1997; 57:615-619.

47. Pastorino JG, Chen ST, Tafani M, Snyder JW, Farber JL. The overexpression of Bax produces cell death upon induction of the mitochondrial permeability transition. J Biol Chem 1998;273: 7770-7775.

48. Tafani M, Schneider TG, Pastorino JG, Farber JL. Cytochrome c-dependent activation of caspase-3 by tumor necrosis factor requires induction of the mitochondrial permeability transition. Am J Pathol 2000;156:2111-2121.

49. Friberg H, Ferrand-Drake M, Bengtsson F, Halestrap AP, Wieloch T. Cyclosporin A, but not FK 506, protects mitochondria and neurons against hypoglycemic damage and implicates the mitochondrial permeability transition in cell death. J Neurosci 1998; 18:5151-5159.

50. He L, Poblenz AT, Medrano CJ, Fox DA. Lead and calcium produce rod photoreceptor cell apoptosis by opening the mitochondrial permeability transition pore. J Biol Chem 2000;275:12175-12184.

51. Heiskanen KM, Bhat MB, Wang HW, Ma J, Nieminen AL. Mitochondrial depolarization accompanies cytochrome $\mathrm{c}$ release during apoptosis in PC6 cells. J Biol Chem 1999;274:5654-5658.

52. Goldstein JC, Waterhouse NJ, Juin P, Evan GI, Green DR. The coordinate release of cytochrome $\mathrm{c}$ during apoptosis is rapid, complete and kinetically invariant. [see comments] Nat Cell Biol 2000;2:156-162.

Received December 2, 2002. Accepted June 12, 2003.

Address requests for reprints to: Xiao-Ming Yin, M.D., Ph.D., Department of Pathology, University of Pittsburgh School of Medicine, 7th Floor, Scaife Hall, Room S749, 3550 Terrace Street, Pittsburgh, Pennsylvania 15261. e-mail: xmyin@pitt.edu; fax: (412) 383-9594.

Supported in part by the Howard Temin Award (K01 CA 74885, National Institutes of Health), R01 CA 83817, National Institutes of Health (to X.-M.Y.), and P01 DK59340, National Institutes of Health (to J.J.L.).

Y.Z. and W.-X.D. contributed equally to this work. 